\title{
От советского до западного трансфера
}

\section{From Soviet to Western Transfer}

In the Hungarian historical literature on socialist agriculture there are two narratives contradicting each other. According to one of them, a special Hungarian type of cooperative was formed in Hungary during the socialist regime. The other argued that through the forced collectivization, the Stalinist kolkhoz was planted in Hungary and it remained unchanged until the collapse of the socialism. To make any progress from these contradicting views, a new approach is needed. The aim of this article is to show the usefulness of comparative and transfer history especially for analysing differences and similarities between the Hungarian cooperatives and the Kolkhoz Model. The concept of transfer became the main analytical category of my research, as it can be used to present both Soviet determinants and Western influences. Although there was a brief period when Hungary, along with the other socialist countries, was so to speak hermetically sealed off from the Western half of Europe, this situation gradually changed after Stalin's death. Following the defeat of the 1956 uprising, Moscow accorded greater room for maneuver in certain matters to the Hungarian leadership in order to prove the superiority and viability of the socialist system. The impact of this kind of "exceptionalism" made itself felt particularly strongly in agrarian policy. Food-supply became a strategic issue for the Kádár régime, which attempted to compensate for its lack of political legitimacy through promises to increase living standards. Thanks to the mediating activity of agrarian lobby a learning process from the West took place from the 1960s. As a result of modern technology and know-how brought into the Hungarian producer cooperatives, which became capable of integrating the developed structures of the capitalist agriculture of the time: closed production systems. By the 1970s internal food supplies became stable and Hungarian agricultural exports began to grow, both to Eastern and Western markets.

Keywords: Hungary, socialist agriculture, cooperative, Kolkhoz Model, transfer, transnational comparison, closed production systems

Zsuzsanna Varga - Professor, Head of the Modern Hungarian History Department, Eötvös Lorand University, email: varga.zsuzsanna@btk.elte.hu 
Тот, кто интересуется характером структурных перемен, которые претерпело венгерское сельское хозяйство во второй половине XX в., скоро сталкивается с тем, что в специальной литературе держатся две противостоящие друг другу точки зрения. ${ }^{1}$ Сторонники подхода, при котором акцентируются достигнутые успехи, признают, что коллективизация сопровождалась экономическим, административным и физическим насилием, но при этом делают упор на производственные достижения, появившиеся с конца 1960-гг., доказывая тем самым модернизационную результативность производственных кооперативов. Подобных успехов в аграрном секторе не удалось добиться ни в одной другой стране социалистического блока. ${ }^{2}$ В результате этого распространилось понятие т. н. «венгерской модели», но в то же время не было точно выяснено, с какого времени и чем она отличалась от служившей образцом советской колхозной системы. Представители другого направления, вырисовывающегося в специальной литературе, сосредоточили внимание на генезисе социалистического сельского хозяйства, подчеркивая, что с помощью повторяющихся насильственных кампаний в Венгрию была пересажена сталинская колхозная система, которая в неизменной форме сохранилась и позже. В эти интерпретационные рамки не вписываются выдающиеся даже по международным меркам производственные результаты 1970-х, 1980-х гг., поэтому исследователи этого направления как правило обходят вниманием этот период в своих работах.

С историографической точки зрения суть проблемы я вижу в том, что сторонники двух направлений выдвигают на передний план разные отрезки сорокалетней истории производственных кооперативов, распространаяя при этом полученные результаты на весь период. Из этого логически следует, что преодолению этих взглядов может способствовать только исследование, охватывающее весь период существования социалистического сельского хозяйства.

Решив написать эту обобщающую работу, охватывающую весь социалистический период венгерского сельского хозяйства, я нуждалась в новом методологическом подходе. В этом отношении я больше всего почерпнула из нового течения под названием

\footnotetext{
${ }^{1}$ Более подробный историографический обзор см.: ZsUZSANNA VARGA, The "Hungarian Agricultural Miracle"? Sovietization and Americanization in a Communist Country. The Harvard Cold War Studies Book Series.(Lanham, Boulder, New York, London: Lexington Books, 2021) xiii-xxi.

${ }^{2}$ См. данные книги, подготовленной с использованием статистики ФАО: A magyar mezögazdaság nemzetközi összehasonlitásban (Budapest: KSH, 1987), 25-28.
} 
transnational comparison, сочетающего результаты сравнительно-исторического метода и изучения трансфера. ${ }^{3} \mathrm{C}$ помощью трансферного подхода я смогла исследовать как процессы советизации, то есть коллективизации сельского хозяйства, так и адаптацию и распространение так называемых замкнутых производственных стстем, ${ }^{4}$ заимствованних из капиталистических стран. Это исследование я дополнила историческим сравнением, то есть систематически сопоставила возникшую в Венгрии форму производственных кооперативов с послужившей образцом колхозной моделью в ключевые моменты четырех изученных десятилетий. ${ }^{5}$

Следовательно, наряду с трансфером, другой важной аналитической категорией стала модель. Обычно историки чуждаются использования моделей, однако в данном случае не было необходимости в создании искусственного идеального типа, поскольку при коллективизации уже существовала модель, представленная примерным колхозным уставом 1935 г. ${ }^{6}$ Сохраняя силу до 1969 г., этот устав стал обязательным образцом, когда, начиная с конца 1940-х гг., Советский Союз навязал странам Центральной и Восточной Европы социалистическую систему сельского хозяйства. С другой стороны, и замкнутые производственные системы, заимствованные с Запада в 1960-1970-х гг. (напр., в области производства птичьего мяса, яиц и кукурузы), с самого начала определялись как модели, поскольку заимствование всех их элементов и правил функционирования предписывалось в обязательном порядке.

При анализе как восточного, так и западного трансфера я пользовалась одинаковой схемой исследования. Прежде всего я определяла первоначальное содержание

\footnotetext{
${ }^{3}$ HeInZ-Gerhard HAUPT, JÜRgEn KoCKA (ed.), Comparative and Transnational History. Central European Approaches and New Perspectives (New York-Oxford: Berghahn Books, 2009)

4 Это название указывает на то, что посредством объединения результатов биологических и технических наук, а также системного подхода в определенных отраслях сельскохозяйственного производства (напр., в производстве птичьего мяса, яиц и кукурузы) были созданы такие замкнутые системы, в которых автоматически регулировались все факторы, влияющие на результативность производства. Благодаря этому возникло сельское хозяйство промышленного типа. MicHAEL TRACY, Government and Agriculture in Western Europe 1880-1988 (3rd edition) (Harvester Wheatsheaf, Hemel Hempstead, UK, 1989).

5 Здесь имеет смысл отметить, что первоначально слово «колхоз» служило собирательным понятием, и лишь позже, когда наиболее распространенной стала одна форма коллективного хозяйствования, артель, это слово стало повсеместно употребляться как ее синоним. ROBERT WILLIAM DAVIES, The Soviet collective farm, 1929-1930 (London: Macmillan, 1980), 75-97, DOI: 10.1007/978-1-349-10255-6_5; Л. В. ИзюмовА, «Государственная политика в контексте социальной модернизации колхозной деревни в 1930-1960-е гг.», в Государственная аграрная политика в России ХX века в контексте модернизаиионного процесса (Вологда: Русь, 2006), 78-101.

6 «Примерный устав сельскохозяйственной артели», в Собрание законов и распоряжений рабочекрестьянского правительства СССР, по. 11 (1935).
} 
трансферных моделей. Затем следовало описание аппарата, служившего посредником и управлявшего осуществлением трансфера. Далее анализировались использованные методы. Наконец, я стремилась показать и адаптационные процессы, интеракции между посредниками и реципиентами трансфера, а также социально-экономические поледствия с учетом территориальных особенностей, скрывающиеся за тенденциями развития в масштабах всей страны.

В настоящей статье я в сжатой форме обобщила свое обширное историческое исследование, охватывающее четыре десятилетия венгерского сельского хозяйства с 1949 по 1989 г. Авторы подавляющего большинства работ о возникновении колхозной системы до сих пор концентрируют внимание скорее на истории коллективизации и лишь в меньшей степени на характерных чертах и функциях самих возникших форм производства. ${ }^{7}$ Я же, со своей стороны, уделила большое внимание изучению принятого в 1935 г. колхозного устава, зафиксировав тем самым однозначную отправную точку для анализа процесса коллективизации в Венгрии, то есть для осуществления сравнения. ${ }^{8}$ Очень полезным оказалось то, что я не ограничила изучение первоначального содержания трансферной модели только колхозом, а поместила его в более широкий контекст всей системы сталинского сельского хозяйства. ${ }^{9}$

С помощью упомянутого выше комплексного подхода удалось изучить больше аспектов советизации венгерского сельского хозяйства, чем когда-либо ранее. Можно утверждать, что все три основные опоры производственной организации (государственные хозяйства, машино-тракторные станции и производственные кооперативы) сталинской аграрной модели сельского хозяйства, сложившейся в начале 1930-х гг., после коллективизации, были почти одновременно перенесены в венгерское сельское хозяйство, в основном опиравшееся на капиталистические отношения собственности, но

\footnotetext{
7 Это хорошо видно из свежего обзора историографии данной темы: CONSTANTIN IORDACHI, ARND BAUERKÄMPER, „The Collectivization of Agriculture in Eastern Europe: Entanglements and Transnational Comparisons", in The Collectivization of Agriculture in Communist Eastern Europe, ed. CONSTANTIN IORDACHI, ARND BAUERKÄMPER (Budapest-New York: CEU Press, 2014), 3-46.

8 Разделенный на восемь глав примерный устав, обнародованный 17 февраля 1935 г., подробно регулировал жизнь колхоза. I. Цели и задачи; II. O земле; III. О средствах производства; IV. Деятельность артели и ее правления; V. O членстве; VI. Средства артели; VII. Организация, оплата и дисциплина труда; VIII. Управление делами артели.

9 Krausz TAMÁs, A Szovjetunió története (Budapest: Kossuth Kiadó, 2008); Lynne Viola, 2014: „Collectivization in the Soviet Union: Specifities and Modalties”, in: Iordachi, Bauerkämper (eds.), The Collectivization of Agriculture, 49-78.
} 
еще хранившее и феодальные элементы. Процесс шел вертикально, сверху вниз. Не было возможности выбирать из нескольких возможных моделей, обязательной стала модель, опиравшаяся на примерный колхозный устав 1935 г. Высокое качество этой модели не могло быть подвергнуто сомнению по идеологическим причинам даже тогда, когда экономические показатели вступили в противоречие с этим постулатом. К тому же трансфер сталинской аграрной модели сопровождался деградацией всей аграрной отрасли до положения «внутренней колонии», то есть ее человеческие и материальные ресурсы были подчинены интересам форсированного развития тяжелой промышленности. ${ }^{10}$ Мое исследование убедительно подтвердило, что в рамках этой модели не только кулаки, но и крестьянство в целом считались гражданами второго сорта. $^{11}$

Переходя к характеристике аппарата, посредничавшего и управлявшего трансфером, нужно отметить, что важной особенностью первого трансферного этапа, начавшегося в 1949 г., было то, что трансфером управляли, с одной стороны, политики, вернувшиеся из московской эмиграции, а с другой стороны, политически надежные кадры, вышедшие из рабочих или бедного крестьянства. На посреднический аппарат до сих пор обращалось мало внимания в специальной литературе. Результаты моего исследования привлекли внимание к тому, что, когда под давлением Советского Союза на повестку дня был поставлен вопрос о пересадке колхозной модели в Венгрию, партийный аппарат был совсем не готов к этому. Из-за антиколхозных настроений венгерского крестьянства партийное руководство в годы после Второй мировой войны замалчивало эту тему не только перед общественным мнением, но и перед членами партии. Нечего и говорить, что в то время государственное управление аграрным сектором выполняло совершенно иные функции. Таким образом, нужно было одновременно подготовить аппарат, посредничающий при осуществлении трансфера (создать соответствующие партийные и государственные органы и наполнить их надежными и разбирающимися в данном вопросе кадрами), и начать сам трансфер. Не приходится удивляться, что при таких предпосылках в ходе трансфера сталинской модели огромная роль выпала на долю, с

\footnotetext{
${ }^{10}$ Font MÁrta, Krausz TAMÁs, Niederhauser Emil, SzVÁk Gyula, Oroszország története (Budapest: Maecenas, 1997), 499-506.; KARL-EUGEN WÄDEKIN, „The Soviet Kolkhoz: Vehicle of Cooperative Farming or of Control and Transfer of Resources", in Cooperative and Commune: Group Farming in The Economic Development Of Agriculture, ed. Peter Dorner (Madison, Wisconsin: University of Wisconsin Press, 1977), 95116.

${ }^{11}$ VARGA ZsUZSANNA, „A falusi társadalom feszültséggócai az 1950-es évek közepén”, Múltunk 51., no. 4. (2006): 223-239.
} 
одной стороны, пропаганды и агитации, а с другой стороны, инициированному сверху государственного насилия, которое все в большей степени получало институциональное оформление. ${ }^{12}$

В Венгрии трансфер советской аграрной модели представлял собой затянувшийся, несколько раз перванный процесс. В течение более десяти лет кампании за коллективизацию (1949-53, 1955-56, 1959-61гг.) сменялись т. н. периодами деколлективизации (1953-54, 1956-58 гг.), когда значительная часть созданных к тому времени производственных кооперативов распадалась, и вышедшие из них крестьяне возвращались к индивидуальному хозяйтвованию. Если этот великий поход за преобразование общества рассматривать как процесс, то выясняется, как менялись с течением времени (отчасти из-за смерти Сталина, отчасти из-за венгерского и польского кризиса 1956 г.) требования советской стороны. Именно поэтому я сознательно разделяю систему социалистического сельского хозяйства на два периода, до и после 1953 г. ${ }^{13}$ Одним из важных политических результатов десталинизации были значительные перемены в отношениях между Советским Союзом и социалистическими странами, в характере влияния СССР на последние. ${ }^{14}$ Если в сталинские времена модель должна была быть скопирована до последней буквы, то Хрущев изменил много элементов модели и в области коллективизации он настаивал лишь формальном осуществлении поставленной задачи, оставляя конкретное исполнение на усмотрение местного руководства. На основании новых исследований можно утверждать, что с 1958 по 1962 г. местные особенности учитывались в гораздо большей степени, чем во время предыдущих кампаниях за коллективизацию. ${ }^{15}$

В результате случилось так, что в Венгрии земля лиц, вступивших в производственный кооператив, пусть в ограниченной форме, но все же оставалась в частной собственности

12 Долгое время это считалось табуированной темой, поэтому не удивительно, что после смены общественного строя ей уделялось повышенное внимание в исследованиях. CM.: JózSEF Ö. KovÁCS, $A$ paraszti társadalom felszámolása a kommunista diktatúrában. A vidéki Magyarország politikai társadalomtörténete, 1945-1965 (Budapest: Korall, 2012); JÓZSEF Ö. KOVÁCS, SÁNDOR HoRVÁTH (szerk.), Állami eröszak és kollektivizálás a kommunista diktatúrában (Budapest: Bölcsészettudományi Kutatóközpont, 2015).

${ }^{13}$ В период до 1953 г. можно говорить о сталинском сельском хозяйстве, а для более позднего времени надлежит пользоваться понятием «советское сельское хозяйство».

${ }^{14}$ Melanie Ilič, Jeremy Smith (ed.), Khrushchev in the Kremlin: Policy and Government in the Soviet Union, 1953-1964 (London -New York: Routlege, 2011).DOI: 10.4324/9780203831793

15 Nigel SwaIN, „Eastern European Collectivisation Campaigns Compared, 1945-1962”, in: Iordachi, Bauerkämper (eds.), The Collectivization of Agriculture, 497- 534. 
за которую кооператив платил ренту. ${ }^{16}$ Это было очень важно, потому что официальная идеология не признавала законности нетрудовых доходов, которым считалась и земельная рента. На последнем этапе коллективизации примерный колхозный устав, действовавший с 1935 г., был изменен в нескольких отношениях. Среди этих изменений нужно выделить то, что был отброшен тезис об обострении классовой борьбы в деревне, и прежние «кулаки» получили возможность вступать в производственные кооперативы. ${ }^{17}$ Тем самым в Венгрии в рамках социалистического сельского хозяйства началась реабилитация традиционных крестьянских профессиональных навыков.

Многократная смена коллективизации и деколлективизации определяющим образом повлияла на трансфер советской модели еще и в том отношении, что с конца 1940-х до начала 1960-х сильно изменился состав и поведение венгерских акторов. В связи с этим нельзя достаточно повторять, что, как вовсе не было однородным «подвергнувшееся нападению крестьянское общество», так не была однородной и коммунистическая партия, стремившаяся к осуществлению советизации.

Исследовательская работа в комитатских архивах, а также использование устной истории очень помогли мне выяснить, какой опыт получило крестьянство в отношении возможностей и пределов борьбы за свои интересы против диктаторской власти. Драматическим примером такого опыта были требования, которые крестьянские общества ясно сформулировали по всей стране в конце октября - начале января 1956 г. ${ }^{18}$ Революция 1956 г. дала важный опыт и руководству, из рядов которого по существу выбыли «московиты». Особенно сильное влияние оказало то, что после 1956 г. окреп новый посредник между властью и крестьянством. Им стало аграрное лобби, понявшее, что руководство во главе с Яношем Кадаром, дававшее обещания повысить уровень жизни, можно убедить извлечь выводы из ошибок сталинистской аграрной политики,

\footnotetext{
${ }^{16}$ A mezögazdasági termelöszövetkezetekre vonatkozó jogszabályok. 1958. január 1.-1959. május 31. (Budapest: Közgazdasági és Jogi Könyvkiadó, 1959), 22.

${ }^{17}$ Во втором пункте одиннадцатого параграфа седьмого закона от 1959 г. говорилось следующее: «Члены производственных кооперативов, которые ранее были эксплуататорами, могут избираться на должности или сохранять свои должности только в том случае, если они заслужили уважение членов кооператива по крайней мере двухлетним примерным трудом в нем. В отдельных случаях из этого распоряжения могут делаться исключения на основании разрешений председателей исполкомов комитатских советов”. Там же, 8.

18 VARga Zsuzsanna, „The Missing Stories from the Rural Hungary in 1956”, in Attila Simon, Slavomír Michálek (ed.), Revolúcia v susedstve: Mad'arská revolúcia v roku 1956 a Slovensko (Bratislava-Budapest: Fórum institút pre vyskum mensín Vydavatelstvo, 2017), 107-118.
} 
проводившейся до 1956 г., и учесть интересы производителей. ${ }^{19}$ Руководство страны во главе с Яношем Кадаром осознало, что без этого было бы невозможно ни долгосрочно снабдить венгерское население продуктами питания, ни обеспечить аграрный экспорт, важный с точки зрения валютных доходов страны.

С помощью примененного мной долгосрочного исследования стало возможным реконструировать то, как адаптировалась и изменялась колхозная модель путем часто скрытых интеракций в принимающей среде. Когда речь идет об интеракциях в рамках партийно-государственного режима, особенно возрастает важность посреднических групп. Именно они играют существенную роль в урегулировании конфликтов интересов представителей власти и групп аграрных производителей. Я различаю две группы посредников. Лайош Фехер руководил деятельностью группы из двадцати-тридцати человек, которая может считаться «внутренним ядром», «генеральным штабом» лоббистов. Его члены располагали влиятельными позициями отчасти в партийном центре, а отчасти в правительственных органах. ${ }^{20}$ Они опирались на гораздо более многочисленный «фундамент», образованный председателями производственных кооперативов, государственными руководителями экономики, комитатскими, уездными партийными и советскими руководителями, учеными, университетскими преподавателями, журналистами и т. д. На основании моих исследований численность этой укорененной на местном уровне группы может быть оценена в 1500-2000 человек. ${ }^{21}$

С помощью подхода, в рамках которого внимание сосредоточивается на интеракциях, доказано, что группы аграрных производителей не были всего лишь пассивными реципиентами навязанной им и совершенно чуждой венгерским условиям советской крупнопроизводственной структуры. Это хорошо показывает процесс, в ходе которого колхозная организация, начиная с начала 1960-х гг., шаг за шагом, но в значительной степени изменилась под давлением крестьян, вынужденно вступивших в производственные кооперативы, и под влиянием лоббистской силы посредников. Это произошло в первую очередь благодаря системе материальной заинтересованности и мелкому сельскохозяйственному производству, а не путем расширения сферы

\footnotetext{
19 VARga ZsuZsanna, Az agrárlobbi tündöklése és bukása az államszocializmus időszakában (Budapest: Gondolat Kiadó, 2013), 53-65.

${ }^{20}$ PAPP ISTVÁN, „Fehér Lajos agrárpolitikusi tevékenysége”, in Magyar agrárpolitikusok a XIX. és a XX. században, szerk. SiPOs LEVENTE (Budapest: Napvilág Kiadó, 2010), 249-263.

${ }^{21}$ VARGA, Az agrárlobbi tündöklése és bukása, 146-148.
} 
сельскохозяйственной деятельности. ${ }^{22}$ Под влиянием этих инициатив «снизу» венгерский сельскохозяйственный кооператив во второй половине 1960 -х гг. превратился в самостоятельную целостность по сравнению с колхозной формой. Это получило официальное подтверждение в III законе от 1967 г.

Особая роль аграрного лобби проявилась не только в том, что оно смогло посредничать в доведении «низовых» кооперативных инициатив до сведения партийного руководства, но и в том, что оно выступало за изучение достижений аграрного развития западных стран. Благоприятный фон для этого создавался тем, что что Хрущев уже с 1954 г. открыл двери Западу, в первую очередь желая купить развитую сельскохозяйственную технологию у США. Из-за программы, нацеленной на то, чтобы догнать и перегнать развитые капиталистические страны, для Хрущева после 1959 г. сильно возросла важность изобретений и методов, способствовавших повышению экономической эффективности. ${ }^{23}$ Это значительно расширило поле маневрирования венгерской аграрной политики.

Особо важную роль посредника в усвоении достижений западной аграрной науки, получивших общее название «зеленой революции», сыграл Исследовательский институт экономики сельского хозяйства при Академии наук Венгрии и его директор, Ференц Эрдеи. Он не случайно считался вторым по значению руководителем лоббистов. ${ }^{24}$ Анализ аграрных экономических исследований того времени показал и то, как изменилось производство знаний благодаря тому, что после 1956 г. партийное руководство уже не требовало от ученых подтверждения идеологических тезисов. ${ }^{25}$

Начало трансфера западных моделей совпало с заключительным этапом трансфера советской модели. В 1960 г. Венгрия купила у западногерманской фирмы «Lohmann» систему производства птичьего мяса и яиц. А во второй половине десятилетия началось

\footnotetext{
22 Tам же, 96-121.

${ }^{23}$ SARi Autio-SARASMO, "Khrushchev and the challenge of technological progress", in ILIČ, SMith (ed.), Khrushchev in the Kremlin, 133-149.; AARON HALE-DORREL, Corn crusade: Khrushchev's farming revolution in the post-Stalin Soviet Union (New York: Oxford University Press, 2018). DOI: 10.4324/9780203831793

${ }^{24}$ Huszár TiBor, Erdei Ferenc 1910-1970. Politikai életrajz (Budapest: Corvina Kiadó, 2012), 397-428.

${ }^{25}$ VARGA ZsuzSANNA, „Agricultural Economics and the Agrarian Lobby in Hungary under State Socialism”, East Central Europe 44 (2017), no. 2-3: 284-308. DOI: 10.1163/18763308-04402003
} 
и налаживание контактов с США, первая система производства кукурузы была закуплена Венгрией в 1969 г. ${ }^{26}$

В рамках западного трансфера в социалистическую плановую экономику были перенесены производственные системы, сложившиеся в капиталистической экономической среде. В ходе своего исследования я применяла ту же систему критериев, что и в случае советского трансфера. Решение о закупке западногерманской и американской производственной системы было принято в сфере высшего политического руководства. Однако мои исследования привлекли внимание и к тому, что, в отличие от заимствования колхозной модели, трансфер западных моделей осуществлялся не сверху вниз. На самом деле он начался снизу, на уровне предприятий, и распространялся горизонтально. Партнерами западных фирм стали государственные хозяйства, производственные кооперативы и их объединения (напр., госхоз «Бабольна», производственный кооператив «Красная звезда» в Надьудваре и т. д.). ${ }^{27}$ Те, в свою очередь, в качестве администраторов систем передавали развитую западную технологию хозяйствам, менее мощным в финансовом отношении. Еще одно отличие между двумя трансферами заключалось в том, что при заимствовании западных производственных систем существовала возможность выбора из нескольких моделей, решающим критерием был экономический результат, эффективность. Важно подчеркнуть и то, что экономические игроки (производственные кооперативы, госхозы) не должны были в обязательном порядке участвовать в данном трансфере, но в то же время они могли быть и пользователями одновременно нескольких производственных систем.

Трансфер западных моделей привел к заметному росту экономических результатов, не случайно, что в западной прессе применительно к Венгрии все чаще употреблялось выражение «венгерская модель». Политики до самого конца официально отрицали существование «венгерской кооперативной модели», Тем не менее, с начала 1970-х гг. силы, стремившиеся затормозить экономические реформы, иногда завуалированно, а иногда открыто брали на прицел именно эти особенности. Очень быстро выяснилось, что заимствование западной производственной технологии изменило мышление его участников, их отношение к рынку и материальной заинтересованности. Несмотря на то, что в 1968 г. был введен Новый экономический механизм, и подверглись изменению

\footnotetext{
${ }^{26}$ VARGA, The “Hungarian Agricultural Miracle”, 201- 207.
}

27 Там же, 294-310. 
определенные идеологические тезисы (о государственной и кооперативной собственности, об общественных и групповых интересах), сам режим партиигосударства, управляемый идеологией, не претерпел существенных изменений. ${ }^{28}$ Для некоторых групп, принимающих решения, сельскохозяйственные производственные кооперативы превратились в раздражающие элементы, чуждые существующему строю.

К началу 1970-х гг. Венгрия с ее Новым экономическим механизмом не просто осталась в одиночестве внутри восточного блока, но и стала объектом повышенного внимания изза опасения, что в ней может повториться чехословацкий процесс. ${ }^{29}$ Без учета центральновосточноевропейского контекста и стремления к советизации региона, усилившегося в брежневскую эпоху, невозможно понять, почему успешная отрасль венгерской экономики, в том числе производственные кооперативы, подверглись столь яростной атаке.

В ходе своей исследовательской работы я рассмотрела различные области (политическую, экономическую, правовую, административную) наступления на производственные кооперативы, остановившись и на его последствиях, в том числе на снятии с должностей руководителей аграрного лобби. Далее, я подробно описала замалчивавшуюся до последнего времени серию постановочных процессов, в ходе которых в 1970-х гг. на скамье подсудимых оказалось более тысячи руководителей кооперативов. ${ }^{30}$

Важно добавить, что это наступление со стороны догматиков временно затормозило, но не смогло остановить процесс трансфера западных моделей, поскольку он развивался не сверху вниз, начавшись из какого-либо центрального ведомства. Зато это наступление крайне ослабило лоббистский потенциал отрасли за счет вытеснения представителей лоббистов из высших органов власти. Вследствие этого способность отрасли защищать свои интересы драматически ослабла. Последствия этого явления по-настоящему сказались в 1980-е гг., когда сельскому хозяйству пришлось взять на себя настолько

\footnotetext{
${ }^{28}$ BEREND T. IVÁN, A magyar gazdasági reform útja (Budapest: Közgazdasági és Jogi Könyvkiadó, 1988), 264305.

${ }^{29}$ FöLDES GYÖRGY, Kádár János külpolitikája és nemzetközi tárgyalásai, 1956-1988. I. (Budapest: Napvilág Kiadó, 2015), $140-152$.

${ }^{30}$ VARGA, Az agrárlobbi tündöklése és bukása, 178-208.
} 
значительную долю в выплате государственного долга, что отрасль снова оказалась в роли «внутренней колонии», напоминающей сталинские времена. ${ }^{31}$

Поначалу производственные кооперативы применили уже опробованную стратегию урегулирования проблемы, а именно: они попытались компенсировать стремления к изъятию их доходов с помощью изменения материальных стимулов, развития приусадебного хозяйствования и вспомогательной деятельности. До начала 1980-х гг. им удавалось поддерживать функционирование структуры, модернизированной с помощью трансфера западных знаний и технологий, и достигать производственных результатов, выдающихся даже по международным меркам. Однако по мере того как на них ложились все бо́льшие тяготы по выплате государственного долга, их резервы начали истощаться. В этой критической ситуации у них не осталось другого выхода, кроме как попытаться выработать качественно новые формы заинтересованности. В центре реформенных предложений, сформулированных на профессиональных форумах, оказалась идея расширить право распоряжения коллективной, кооперативной собственностью. Общеизвестно, что решения, затрагивавшие отношения собственности, могли приниматься только на политическом уровне, в высшем органе принятия политических решений, в Политбюро. Специалисты напрасно вносили свои предложения, органы партийного центра, отвечавшие за экономическую политику, уже не смогли вынести их на повестку дня совещаний высших руководителей. ${ }^{32}$ Политбюро и ЦК партии снова и снова давали ясно понять, каких идеологических аксиом они настойчиво придерживаются. Партийное руководство правильно понимало, что, в качестве следующего шага после пересмотра отношений собственности может быть подвергнута сомнению господствующая роль партии.

После смены общественного строя в Венгрии был осуществлен другой сценарий. В 1990 г., после превращения оппозиционных движений в партии и переговоров за круглым столом, проведенных по польскому образцу, состоялись первые свободные выборы. Новое правительство ясно дало понять, что инициирует радикальные перемены в отношениях собственности во всех отраслях экономики, в том числе и в сельском хозяйстве. В результате реституции и приватизации в течение нескольких лет была

\footnotetext{
${ }^{31}$ Интервью автора с Имре Димени, 17 октября 2011 г. Интервью автора с Иштваном Сабо, 1 февраля 2013 $\Gamma$.

${ }^{32}$ VARGA, Az agrárlobbi tündöklése és bukása, 228-252.
} 
восстановлена аграрная структура, опирающаяся на частную собственность. Однако способ осуществления этих перемен вверг в длительный кризис не только аграрную отрасль, но и широкие массы сельского общества. Тяжелые последствия по сей день присутствуют в жизни сельского общества. ${ }^{33}$

${ }^{33}$ KovÁCH IMRE, A vidék az ezredfordulón. A jelenkori magyar vidéki társadalom szerkezeti és hatalmi változásai (Budapest: Argumentum, 2012). 